\title{
$\mathrm{AOP}$ 를 이용하여 진화된 프로그램의 회귀테스트 기법
}

\author{
이 미 진 ${ }^{+} \cdot$ 최 은 만 ${ }^{++}$ \\ 요 약
}

관점지향 프로그래밍 $(\mathrm{AOP})$ 은 횡단 관심사까지 모듈화 하여 소프트웨어의 모듈화를 높여주는 새로운 프로그래밍 패러다임이다. 이를 이용하 면 레거시 시스템에 손대지 않고 소프트웨어를 확장시킬 수 있다. 관점지향 프로그래밍 자체 혹은 레거시 시스템만의 테스트 기법은 많이 있으 나 확장된 프로그램의 테스트 기법에 대해선 많은 연구가 진행되지 않고 있다. 이 논문에서는 관점지향 프로그래밍을 이용하여 소프트웨어를 확장한 경우의 테스트 기법에 대해 관점지향 프로그래밍의 결함 모델에 맞춰 제시한다. 우선 $\mathrm{AOP}$ 의 반사기능의 객체를 이용하여 교차점 패턴 의 부정확한 강도 및 부정확한 애스펙트의 우선순위를 테스트하고, 증명 규칙을 이용하여 기대하는 사후 조건 성립의 실패에 대해 테스트하였 다. 또한 set() 교차점을 이용하여 불변 조건 보존의 실패에 대해 테스트하고, 제어흐름 그래프를 이용하여 제어 의존의 부정확한 변형에 대해 확인하는 방법을 제시한다. 실증을 위하여 셋탑박스의 채널 관리 시스템을 구현하여 제시한 각각의 테스트 기법들에 대해 실험하였다.

키워드 : 관점 지향 프로그래밍, 회귀테스트, 소프트웨어 진화

\section{Regression Testing of Software Evolution by AOP}

\author{
Lee, Mi $\operatorname{Jin}^{\dagger} \cdot$ Choi, Eun Man ${ }^{\dagger+}$
}

\begin{abstract}
Aspect Oriented Programming(AOP) is a relatively new programming paradigm and has properties that other programming paradigms don't have. This new programming paradigm provides new modularization of software systems by cross-cutting concerns. In this paper, we propose a regression test method for program evolution by AOP. By using JoinPoint, we can catch a pointcut-name which makes it possible to test the incorrect pointcut strength fault and the incorrect aspect precedence fault. Through extending proof rules to aspect, we can recognize failures to establish expected postconditions faults. We can also trace variables using set() and get() pointcut and test failures to preserve state invariant fault. Using control flow graph, we can test incorrect changes in control dependencies faults. In order to show the correctness of our proposed method, channel management system is implemented and tested by using proposed methods.
\end{abstract}

Key Words: Aspect-Oriented Programming, Regression Test, Software Evolution

\section{1. 서 론}

빠르고 효율적인 소프트웨어 개발을 위해 프로그래밍 기 법은 점점 모듈화 되는 방향으로 발전되었다. 현재 많이 사 용되고 있는 객체지향 프로그래밍 패러다임은 핵심 관심사의 모듈화를 지원해준다. 이는 핵심 기능을 하나의 모듈로 구현 하여 다른 기능을 가진 모듈과 분리함으로써 프로그램을 효 율적으로 작성하고 관심사 별로 재사용이 가능하도록 도와준 다. 그러나 객체지향 프로그래밍 패러다임만으로는 완벽한 관심사의 분리가 어렵다. 예를 들어 객체지향 프로그래밍에 서 소매 애플리케이션에서 구매와 재고관리를 하는 핵심 관 심사는 모듈화 시킬 수 있지만, 시스템 전체에 필요한 로깅,

† 준 회 원 : 동국대학교 대학원 컴퓨터공학과(공학석사)

†† 정 회 원: 동국대학교 컴퓨터공학과 교수

논문접수:2008년 4월 1일

수 정 일 : 1 차 2008 년 5 월 14 일

심사완료 : 2008년 5월 26일
인증 등의 횡단 관심사의 경우 모듈화 시킬 수 없다[6].

Aspect Oriented Programming(AOP)[7]은 이러한 문제를 해결하기 위해 고안된 프로그래밍 패러다임이다. $\mathrm{AOP}$ 는 여 러 핵심 관심사에 걸쳐 나타나는 횡단 관심사를 애스펙트 (Aspect)라는 모듈화 단위로 지원하고 있다. 이를 통해 핵심 관심사뿐만 아니라 횡단 관심사까지 모듈화 하여 프로그램 의 재사용을 높여준다. 또한 $\mathrm{AOP}$ 는 별도로 정의된 관심사 들이 필요에 의해 언제나 동적으로 플러그인(plug-in) 될 수 있게 해주는 웨이빙(weaving) 메커니즘을 가지고 있다. 이 러한 장점으로 인해 $\mathrm{AOP}$ 를 적용하면 프로그램의 보안과 같 은 특정 관점의 테스트를 애스펙트로 정의하여 동적으로 테 스트 할 수 있다. 또한 $\mathrm{AOP}$ 는 일반적인 모듈의 단위 테스 트나 컴포넌트의 빌트인 테스트(built-in test) 등에도 적용 할 수 있다[1,2,10].

한편 횡단 관심사를 독립적으로 처리할 수 있는 $\mathrm{AOP}$ 의 웨이빙 메커니즘을 잘 이용하면 레거시 시스템을 수정을 가 


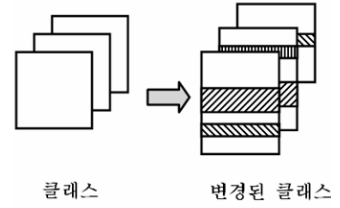

(a) 일반적인 진화

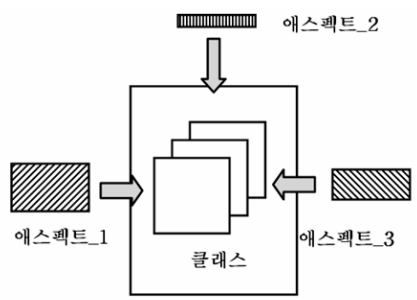

(b) $\mathrm{AOP}$ 를 이용한 진화
(그림 1) AOP를 이용한 진화

하지 않고 확장시키거나 진화시킬 수 있다. (그림 1)에 보는 바와 같이 순수한 확장이나 진화는 소프트웨어를 구성하는 각 요소 안을 수정하거나 추가하지만, $\mathrm{AOP}$ 는 레거시 부분 에 수정을 가하지 않고 독립된 애스펙트를 정의하여 웨이빙 에 의해 시스템을 구성할 수 있다. 레거시 시스템과 별도로 독립적으로 개발할 수 있고 별도의 모듈로 정의할 수 있는 애스펙트의 장점을 이용하면 동적인 웨이빙도 가능하다. 따 라서 최근에는 실행 중인 시스템의 확장이나 테스트에 대한 연구 사례가 발표되고 있다[3].

이와 같이 $\mathrm{AOP}$ 의 장점을 이용해 프로그램을 확장한 경 우, 확장한 프로그램을 어떻게 테스트해야 할까? (그림 1)의 (a)와 같은 일반적인 확장의 경우 실행경로를 분석하여 추 가 또는 변경된 부분이 있는 곳은 다시 새로운 테스트케이 스를 만들어 시험하고, 또한 변경이 없더라도 영향 받는 부 분을 찾아 이를 다시 테스트 할 수 있다. 이러한 경우의 테 스트 방법은 이미 많은 연구가 진행되어 있다. 그러나 (b)와 같이 애스펙트 형태로 확장될 때 레거시 시스템의 테스트 방법에 대한 연구는 아직 미비하다. 이 논문에서는 이처럼 레거시 시스템에 애스펙트 형태로 확장될 때 테스트해야 하 는 테스트 범위와 그에 맞는 테스트 방법을 제시하고 있다.

논문의 진행은 다음과 같다. 2 장에서는 논문을 위한 배경 지식에 해당하는 $\mathrm{AOP}$ 와 회귀테스트에 대해 간단히 설명하 고 있다. 3장에서는 논문의 핵심 주제인 테스트 범위 및 테 스트 방법에 대해 소개한다. 각각의 결함 타입에 맞는 테스 트 방법을 간단한 예를 통해 보여주고 있다. 4장에서는 3장 에서 제시한 테스트 방법을 간단한 시스템을 통해 적용시켜 실험하였다. 5장은 테스트 결과 및 결론을 기술한다.

\section{AOP을 이용한 확장과 회귀테스트}

관점지향 프로그래밍은 횡단 관심사를 모듈화 하기 위하 여 객체지향 프로그래밍과 프로시저 프로그래밍의 기초 위 에 이것들의 개념과 구성물을 확장한 것이다. 관점지향 프 로그래밍에서도 핵심 관심사는 기존의 선택된 기본 방법론 으로 구현한다. 예를 들어, 객체지향 프로그래밍이 기본이라 면 핵심 관심사는 클래스로 구현된다. 그러나 횡단 관심사 는 관점지향 프로그래밍으로 구현된다.

횡단 관심사를 관리하는데 객체지향 프로그래밍과 관점지 향 프로그래밍의 근본적인 차이점은 관점지향 프로그래밍에
서는 각 관심사를 구현하는 모듈이 자신에게 적용되는 횡단 관심사를 전혀 모른다는 사실이다. 예를 들어, 비즈니스 로직 모듈은 자신의 메서드가 로깅이 되고 있는지 또는 사용자 인 증을 하고 있는지 전혀 모르게 된다. 따라서 각 관심사가 독 립적으로 발전해 나갈 수 있으며 이러한 이유로 $\mathrm{AOP}$ 를 이 용한 확장 방법이 제안되었고 많이 사용하고 있다 $[1,2,4]$

유지보수 단계에서 오류를 발견하고, 환경을 변화시키고, 기능을 추가하는 등 여러 가지 변경 요인에 의해 원래의 프 로그램에 수정을 가하게 된다. 이미 테스트를 마친 프로그램 에 수정, 변경을 가한 후 의도하지 않았던 오동작이나 새로 운 오류를 일으키는지 확인하기 위한 테스트를 회귀테스트라 하며 여기에는 두 가지 요소가 있다. 첫 번째는 오류를 발견 하고 고치고 다시 원래 문제를 일으켰던 것을 테스트 해 보 는 것이며 두 번째 요소는 수정된 부분이 다른 부분에 영향 을 주지 않는다는 것을 확인하는 것이다. 이 논문에서 말하 는 회귀테스트의 의미는 후자의 것으로, 이러한 의미의 테스 트는 수정 작업이 성공적으로 이루어졌는지 확인하는 것이 아니라 수정 후 프로그램의 통합이 제대로 이루어졌는지 확 인하는 작업이다. $\mathrm{AOP}$ 로 확장하는 경우, 확장하기 위해 추 가한 애스펙트의 테스트는 그렇게 큰 의미를 가지지 않는다. 그보다는 $\mathrm{AOP}$ 로 확장 이후 확장을 위해 추가된 애스펙트들 이 원래의 레거시 시스템과 웨이빙 되어 레거시 시스템에 의 도하지 않은 오류가 생성되는지 확인해야 한다.

\section{AOP 결함 모델을 기반으로 한 테스트 기법}

$\mathrm{AOP}$ 는 결합점에 교차점과 충고로 프로그램이 확장된다. 이러한 $\mathrm{AOP}$ 의 특성으로 인해 새로운 결함이 나타나게 된 다. 이와 같은 결함에 대해 잘 정의해 놓은 것을 결함 모델 이라 한다. 이러한 결함 모델은 프로그래머가 범하기 쉬운 결함에 대해 인지하고 피할 수 있도록 도와준다. 또한 프로 그래머가 결함을 피하지 못한 경우라도 결함 모델은 테스터 가 결함을 쉽게 발견하고 찾을 수 방법을 제시해준다. 이 논문에서도 $\mathrm{AOP}$ 를 이용해 진화된 프로그램의 회귀테스트 방법을 제시하기 위해 $\mathrm{AOP}$ 결함 모델을 이용하였다.

$\mathrm{AOP}$ 의 결함 모델은 $[5,11,16]$ 에서와 같이 현재 여러 정의 가 나와 있지만 가장 현실적으로 타당한 [5]에서 제시한 <표 $1>$ 과 같은 결함 모델을 따르기로 한다.

교차점과 충고는 각각 그 자체만으로는 의미가 없다. 충 고에 교차점을 작성하여 그 교차점에서 선택된 결합점에 충 고가 적용되는 것이다. 다시 말하면, 충고는 교차점에서 선 택한 모든 결합점에서 실행된다. 이때, 교차점이 올바른 결 합점을 선택하고 있지 않을 경우 [14]에서와 같이 잘못된 교 차점 패턴 강도를 갖게 된다. 이러한 교차점 패턴의 부정확 한 강도 결함을 테스트하기 위해, $[8,9]$ 에선 상태모델을 이 용하여 교차점의 패턴 강도 결함을 테스트하고 있다. 그러 나 모든 상태 경로에 대해 직접 상태모델을 작성해야 하기 때문에 시간이 많이 소요될 뿐만 아니라 작성하는 과정에서 또 다른 오류가 생성될 수 있다. 이 논문에서는 정확하고 
〈표 1〉결함 모델과 테스트 방법

\begin{tabular}{|l|l|l|l|}
\hline \multicolumn{1}{|c|}{ 결함의 종류 } & \multicolumn{1}{|c|}{ 설명 } & \multicolumn{1}{|c|}{ 알려진 테스트 방법 } & \multicolumn{1}{c|}{ 이 논문에서 제안된 방법 } \\
\hline \hline 교차점 패턴의 부정확한 강도 & $\begin{array}{l}\text { 결합점 선택을 위한 패턴이 너무 강하거나 약 } \\
\text { 하면 발생하는 오류 }\end{array}$ & - 상태모델의 이용[8, 9] & - 반사기능 객체를 이용한 테스트 \\
\hline 부정확한 애스펙트 우선순위 & $\begin{array}{l}\text { 애스펙트의 충고들이 동일한 결합점에 적용되 } \\
\text { 는 경우 우선순위를 프로그램에 정확히 작성하 } \\
\text { 지 않으면 우선순위가 틀리게 적용되는 오류 }\end{array}$ & & - 반사기능 객체를 이용한 테스트 \\
\hline 기대하는 사후 조건 성립의 실패 & $\begin{array}{l}\text { 횡단 메커니즘에 의해 충고가 삽입된 메서드의 } \\
\text { 사후 조건은 장담할 수 없게 됨 }\end{array}$ & - 증명 규칙을 이용 \\
\hline 불변 조건 보존의 실패 & $\begin{array}{l}\text { 횡단 메커니즘으로 인하여 Invariant가 깨지는 } \\
\text { 오류 }\end{array}$ & $\begin{array}{l}\text { - 상태모델 적용[11, 12] } \\
\text { - 데이터흐름 그래프 이용[3] }\end{array}$ & - Set 교차점 이용 \\
\hline 제어 의존의 부정확한 변형 & 대체중고에 의한 제어흐름의 변형 오류 & - 제어흐름 그래프를 이용[17, 18] & - 제어흐름 그래프를 이용 \\
\hline
\end{tabular}

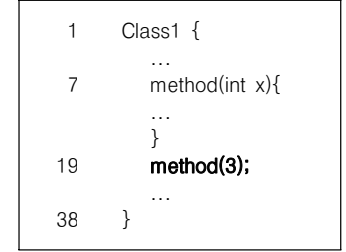

(a) Class1의 소스코드 위치

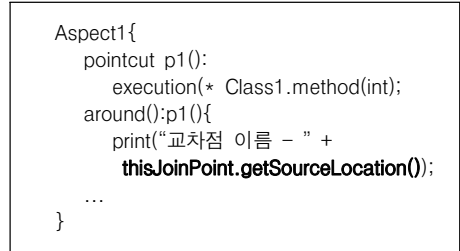

(b) AspectJ 반사기능 객체의 사용
$\Rightarrow$ Result: 교차점 이름 - Class1.java:19

\section{(그림 2) Aspect 반사기능의 객체 사용}

효율적인 테스트를 위해서 $\mathrm{AOP}$ 에서 지원하는 반사기능의 객체를 사용하였다.

교차점 패턴 강도를 테스트하기 위해 현재 작성된 교차점 이 어떤 결합점들을 선택하고 있는지 알아야 한다. 특정 교 차점이 선택해야 하는 결합점들을 미리 작성해본 후, 그 교 차점이 실제로 어떤 결합점들을 선택하고 있는지 비교할 수 있다면 교차점 패턴 강도 결함을 확인할 수 있다. (그림 2) 는 AspectJ의 반사기능의 객체인 thisJoinPoint의 사용을 보 여주고 있다. (그림 2)의 (b)에서 $\mathrm{pl}$ ()이라는 교차점은 Class1 클래스의 method(int) 메서드의 호출을 결합점으로 가지고 있다. 이때 $\mathrm{pl}($ )이 적용되는 충고 내에 thisJoinPoint 반사객체 의 getSourceLocation()을 작성하여 확인하면 $\mathrm{p} 1$-Class1.java: 19 와 같은 결과를 확인할 수 있다. 이와 같은 방식으로 $\mathrm{pl}($ ) 교차점이 실행될 때의 결합점을 찾아 $\mathrm{pl}($ )의 교차점명세와 비교해 보면 부정확한 애스펙트 패턴 강도 결함을 찾아볼 수 있다.

결합점에 두 개 이상의 애스펙트가 적용되고 있는지, 그 지점에서 실제 애스펙트가 어떤 순서로 실행되고 있는지 밝 혀내기 위한 방법으로 앞서 교차점 패턴 강도 결함을 밝혀내 기 위해 사용했던, $\mathrm{AOP}$ 의 반사기능의 객체를 통해 가져온 데이터를 이용하고 있다. 특정 충고가 수행될 때, 수행되는 충고에서 적용되고 있는 교차점의 이름과 충고가 수행되는 결합점의 위치정보를 충고가 수행되는 순서로 수집한다. 이 를 결합점의 위치정보를 기준으로 하여 정렬하면 하나의 결 합점에서 적용되는 교차점의 이름이 실행되는 순서대로 나열 된다. 이 데이터를 이용하면 특정 결합점에 적용되는 애스펙 트 및 애스펙트의 우선순위까지도 한 번에 확인할 수 있다.

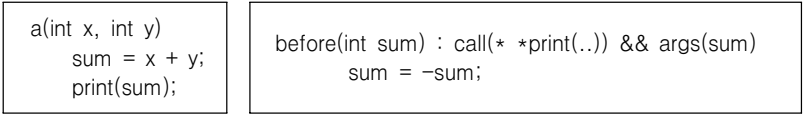

(그림 3) a() 메서드와 애스펙트

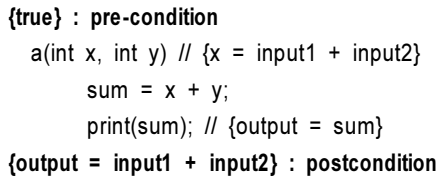

(그림 4) a() 메서드와 사후 조건

각 클래스 혹은 메서드는 메서드가 끝날 때 만족되어야 하는 사후 조건(post-condition)을 가지고 있다. 레거시 시스 템에서 사후 조건이 만족되었다 하더라도 애스펙트의 횡단 메커니즘에 의해 충고가 삽입된 메서드의 사후 조건은 장담 할 수 없게 된다. (그림 3)의 $\mathrm{a}($ ) 메서드와 메서드에 삽입된 애스펙트를 보면, $\mathrm{a}()$ 메서드는 두 개의 변수를 받아 그 두 개의 변수의 합을 구한 후 출력해 주는 메서드이다. 이 메 서드의 사후 조건이 입력받은 두 수를 더한 값을 출력해 주 는 것이라 하면, $\mathrm{a}()$ 메서드 자체만으로는 사후 조건이 만족 되지만 그 충고의 삽입으로 인해 $\operatorname{print}()$ 메서드가 호출될 때 sum 값을 입력받아 -sum 값을 되돌려 주기 때문에 결 국 -sum이 출력되어 사후 조건이 지켜지지 않게 된다.

사후 조건 성립에 대한 결함을 테스트하기 위하여 (그림 4)에 $\mathrm{a}()$ 메서드와 같이 증명 규칙을 적용한다. 증명 규칙은 소스 코드를 수학적으로 증명해 나가는 것이다.

애스펙트는 이전, 대체, 이후 충고로 결합점에 삽입된다. 다 시 말하면 특정 결합점의 이전이나 이후에 혹은 대체하여 충 고에 해당하는 코드가 삽입되는 것이다. 따라서 충고의 종류에 따른 위치에 충고의 내용을 삽입하여 증명 규칙을 적용하면 애스펙트까지 확장한 사후 조건의 테스트가 될 수 있다. (그림 5)의 (a)는 애스펙트의 before() 충고이고 (b)는 $\mathrm{a}($ () 메서드 상 에서 충고의 내용 삽입이 나타나 있다. 이렇게 메서드에 애스 펙트를 직접 삽입하여 증명 규칙을 적용하면 (그림 6)과 같이 된다. 현재의 $\mathrm{a}()$ 메서드의 사후 조건은 \{output=input $1+$ input2\}이지만, 애스펙트가 삽입된 회색바탕의 코드에 의해 사후 조건에 맞지 않음을 확인할 수 있다. 


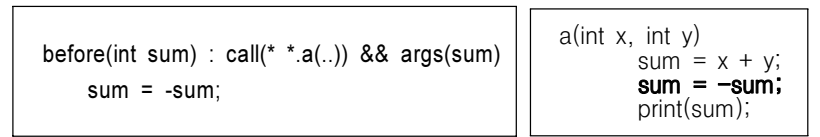

(a) 애스펙트의 before() 충고 (b) 애스펙트 코드 삽입

(그림 5) 애스펙트 삽입과 레거시 프로그램에 삽입된 코드

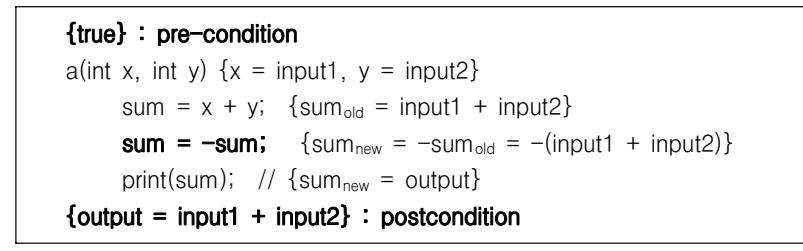

(그림 6) 애스펙트 확장된 프로그램에 증명 규칙 적용

pointcut trace(object variable) : set(object class.variable) \&\& args(variable)

(그림 7) $\operatorname{set}($ ) 교차점과 $\operatorname{args}($ ) 매개변수 교차점

불변 조건 보존의 실패 결함을 테스트하기 위해 $[8,9]$ 에 서와 같이 전체 프로그램에 모두 상태모델을 적용하기는 어 렵다. 그것은 상당히 복잡할 뿐만 아니라 실제프로그램의 실행에는 생각지 못한 변수가 있어 값이 어떻게 변할지 예 측하기 어렵기 때문이다. 또 [3]의 데이터흐름 그래프를 통 해 데이터흐름을 확인하는 방법은 복잡할 뿐 아니라 아직 실현되지 못하였다. 따라서 이 논문에서는 간단하고 실현 가능한 방법으로 set() 교차점을 이용하여 프로그램이 실제 실행되는 동안의 불변 조건을 검사할 수 있는 방법을 제시 하였다.

먼저 불변 조건 보존의 실패 결함을 테스트하기 위해 set() 교차점을 적용하여 인스트루멘트를 작성하였다. $\operatorname{set}()$ 교차점 필드 쓰기 교차점으로, 지정한 필드에 쓰기참조가 일어난 경우를 포착한다. (그림 7)은 필드 쓰기 교차점으로, 단순히 쓰기 참조가 일어나는 점만 포착하는 것이 아니라, $\operatorname{args}()$ 교차점을 통해 새로 쓰여진 필드의 값을 넘겨받아 보여줄 수 있다.

$\mathrm{AOP}$ 의 충고 중 대체 충고는 결합점에 해당하는 내용 자 체를 대체해서 수행되는 것이다. 따라서 이러한 대체 충고 를 이용하면 결합점에 새로운 코드가 삽입되어 명령문 사이 의 의존 관계를 대신하는 새로운 분기를 만들 수도 있고, 새로운 데이터도 삽입시킬 수 있어 메서드의 제어흐름을 상 당히 변경시킬 수 있다.

(그림 8)은 Class1 클래스와 그 내부의 method1() 메서드 에 대한 제어흐름 그래프이다. 여기에 (그림 9)의 (a)와 같 은 애스펙트를 이용하여 시스템을 진화시킨 경우 (그림 9) 의 (b)에서 보는 바와 같이 제어 의존의 변화를 확인할 수 있다. 이와 같은 제어 의존도의 변화가 예상치 못하게 생겨 날 경우 찾아내기 어려운 결함이 될 것이다.

제어 의존을 확인하기 위해서는 우선 제어흐름 그래프를 그려봐야 한다. [17,18]역시 제어 의존의 부정확한 변형을 테스트하기 위해 상태모델을 기반으로 한 애스펙트 흐름그

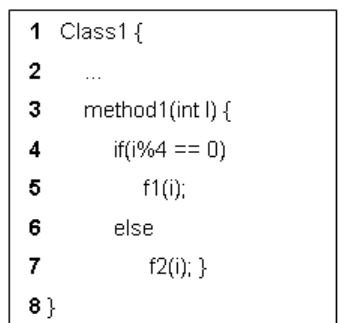

(a) Class1클래스

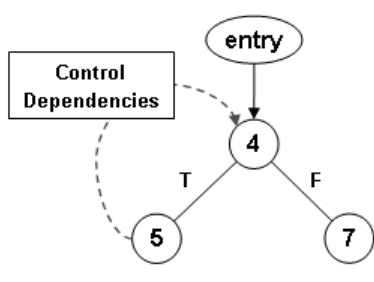

(b) $\operatorname{method} 1$ () 메서드의 제어 의존도
(그림 8) method1()의 제어흐름 그래프

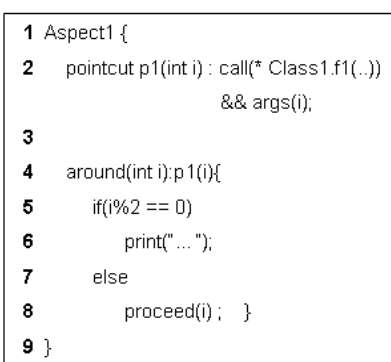

(a) Aspect1 매스펙트

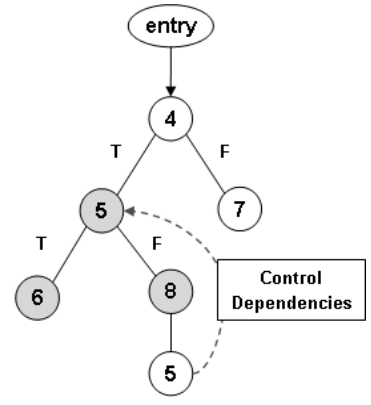

(b) 애스펙트 삽입 후 제어 의존도
(그림 9) 애스펙트 추가된 제어흐름 그래프

래프를 작성하였는데 이 논문에선 간단한 소스코드를 이용 하여 제어흐름 그래프를 애스펙트로 확장하여 작성하고 있 다. 애스펙트 확장 후의 제어흐름의 변화를 보기 위해 우선 (그림 8)과 같이 애스펙트가 삽입될 결합점에 해당하는 레 거시 시스템의 제어흐름 그래프를 작성해야 한다. 그 후 삽 입될 애스펙트의 제어흐름 그래프를 작성하여 (그림 9)에서 보이는 바와 같이 레거시 시스템의 제어흐름 그래프에 애스 펙트 제어흐름 그래프를 삽입한다. 그 후 다시 제어 의존도 를 살펴보면 애스펙트 추가 후의 제어 의존도를 확인해 볼 수 있다.

\section{AOP를 이용하여 진화된 프로그램의 회귀테스트 실험}

이 장에서는 실험을 통해 $\mathrm{AOP}$ 를 이용하여 진화된 프로 그램의 회귀테스트 방법을 보인다. 실험을 위해 간단한 셋 탑박스 채널관리시스템을 작성하였다. Java 언어를 이용하 여 레거시 시스템을 작성하고 AspectJ를 이용하여 시스템을 확장하였다. 이 논문에서 제시하고 있는 회귀테스트 기법의 현실성을 입증하기 위하여 결함을 주입하고, 테스트를 통해 결함을 확인한다.

\section{1 단계 1: 레거시 시스템 구현}

관점지향 프로그래밍을 이용한 확장을 테스트하기 위해 우선 레거시 시스템을 설계하였다.

간단한 셋탑박스 관리 시스템은 (그림 10)과 같이 전원 관리와 채널 검색, 채널 이동의 기능을 가지고 있다. 전원 관리 기능은 사용자가 전원을 켜고 끌 수 있도록 해준다. 채널 검색 기능을 사용하면 시그널로부터 채널을 가져와 채 

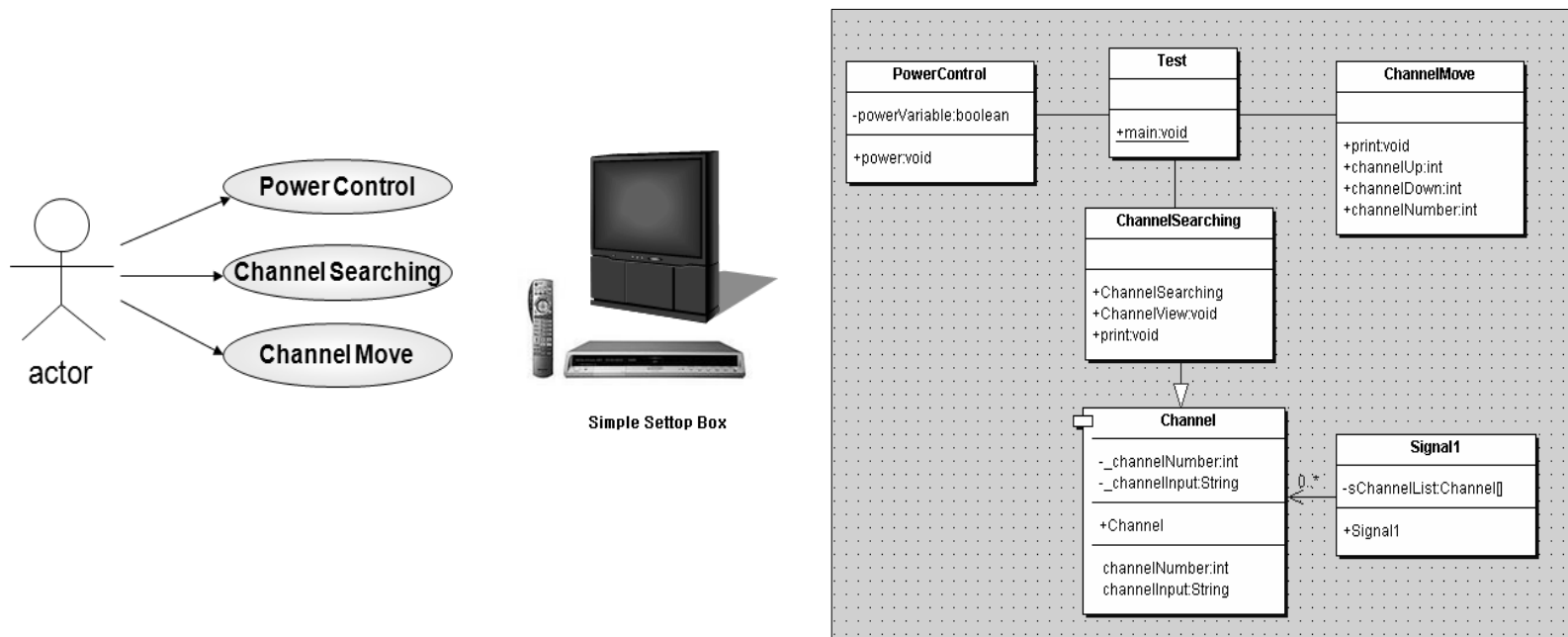

(그림 10) 레거시 시스템의 유즈케이스 다이어그램 및 클래스 다이어그램

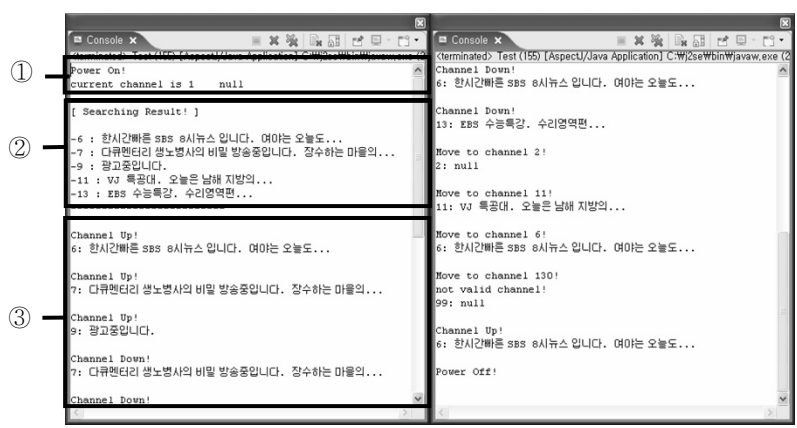

(그림 11) 레거시 시스템의 실행 결과

널을 검색하고, 시그널로부터 채널을 가져오기 위해 채널 검색 기능을 수행하면 현재 시그널에 존재하는 채널 목록을 가져올 수 있다. 이렇게 가져온 채널 목록 안에서 채널의 이동이 가능한데, 채널을 위로, 아래로 그리고 채널 번호로 이동하는 세 가지 기능을 제공한다.

(그림 10)에 나타난 레거시 시스템의 클래스 다이어그램 과 같이 Test 클래스에서 PowerControl 클래스의 PowerOn() 메서드를 호출하면 (그림 11)의 (1)과 같이 전원이 켜지고 현 재 채널이 나타나게 된다. ChannelSearch 클래스를 수행하 면 Signal 클래스로부터 신호를 읽어와 채널 목록을 만들고 만든 채널 목록을 $\operatorname{print}($ ) 메서드를 이용해 (그림 11)의 (2)처 럼 출력해 준다. ChannelMove의 Channel $\mathrm{Up}($ ), ChannelDown(), ChannelNumber() 메서드를 호출하면 각각 채널을 위로, 아 래로, 번호에 맞게 수정한 후에 ChannelMove클래스 내의 $\operatorname{print}($ ) 메서드를 이용해 (그림 11)의 (3)과 같이 화면에 채널 번호와 데이터를 출력해 준다.

\section{2 단계 2: $\mathrm{AOP}$ 확장}

Java언어로 작성한 레거시 시스템에 관점지향 프로그래밍 기 법을 이용해 시스템을 확장하였다. 확장된 기능 중 AdultLock 기능은 성인채널을 잠그는 역할을 하고, ChannelLock 기능은 유료채널을 잠그는 역할을 한다. AdultLockAspect에선 성인채 널 목록을 만들어 성인채널 목록에 있는 채널로 이동한 경

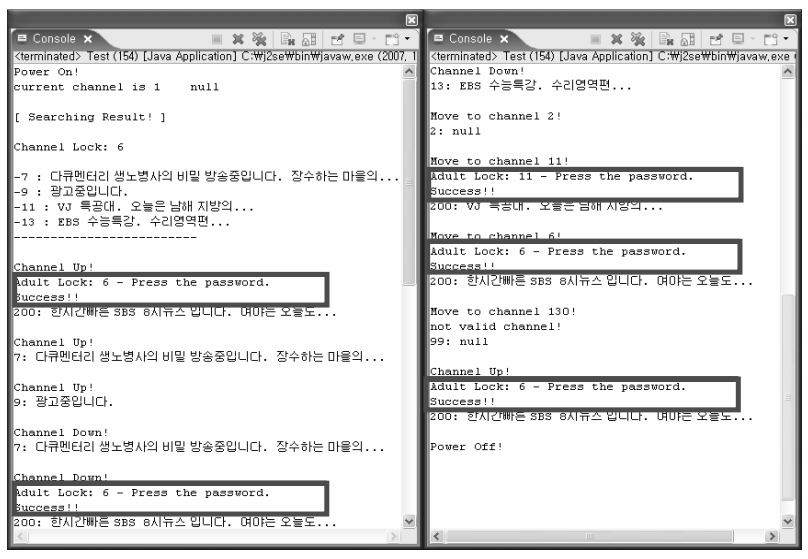

(그림 12) $\mathrm{AOP}$ 를 이용하여 확장된 프로그램의 수행결과

우 암호를 입력받아 암호가 맞는 경우 화면을 보여준다. ChannelLockAspect는 유료채널 목록을 만들어 유료채널일 경우 유료메시지가 나타나고 해당 채널을 볼 수 없게 한다. AdultLock과 ChannelLock이 동시에 걸려있는 채널의 경우 항상 ChannelLock이 AdultLock보다 우선해야 한다. 채널 중 6, 11번에 AdultLock 기능을 적용하였고, 6 번에 Channel Lock 기능을 적용하였다. (그림 12)는 애스펙트를 확장해서 프로 그램을 실행한 경우의 실행결과이다.

\section{3 단계 3: 결함의 발견 및 회귀테스트 기법 적용}

앞서 Java언어를 기반으로 한 간단한 셋탑박스 채널 관 리 시스템을 구현하고, 레거시 시스템에 AspectJ를 이용해 기능을 확장시켰다. 이처럼 $\mathrm{AOP}$ 를 이용해 프로그램을 확장 한 경우, $\mathrm{AOP}$ 만의 특징으로 인해 기존의 프로그래밍 메커 니즘과는 다른 새로운 결함이 생겨나기 때문에 $\mathrm{AOP}$ 결함모 델에 맞는 회귀테스트가 진행되어야 한다. 이 장에서는 앞 서 작성한 간단한 셋탑박스 채널 관리 시스템에서 나타나는 결함을 $\mathrm{AOP}$ 결함 모델을 기반으로 하여 인위로 만들어 보 고, 3장에 제시한 테스트 기법들을 적용하여 결함을 찾을 수 있음을 보인다. 
4.3.1 AOP 반사기능의 객체를 이용한 교차점 패턴 강도 및 애스펙트 우선순위 테스트

실험을 통해 발견되는 교차점 패턴 강도 및 애스펙트 우 선순위 결함을 보이고 테스트방법을 적용하여 테스트하였 다. 실험방법 및 결과는 다음과 같다.

\subsubsection{1 교차점 강도 결함의 발견}

(그림 13)은 AdultLockAspect 애스펙트의 일부소스이다. adultChannel() 교차점에서 선택되어야 하는 결합점은 <표 2>에 명시된 바와 같이 ChannelMove 클래스의 print() 메 서드가 호출될 때 이다. (그림 13)의 adultChannel() 교차점의 패턴을 보면 ChannelMove 클래스의 print() 메서드가 호출될 때가 결합점으로 취해지고 있는데, 현재시스템의 ChannelMove 클래스의 print() 메서드는 하나밖에 존재하지 않기 때문에 adultChannel() 교차점은 올바른 결합점을 취하고 있다.

channelLockAspect 애스펙트의 lockedChannel() 교차점 역시 <표 2>의 교차점 명세에 나타난 바와 같이 adultLockAspect 애 스펙트의 adultChannel() 교차점과 동일한 교차점을 선택하고 있어야 한다. 그러나 lockedChannel() 교차점의 필드 서명을 보면 (그림 13)의 회색바탕의 코드 내용과 같이 call(**. $\operatorname{print}())$ 로 작성되어 있다. 만약 현재 시스템에서 $\operatorname{print}()$ 메 서드가 하나만 존재한다면 현재의 필드 서명은 명세에 맞는 결합점을 선택하고 있을 것이다. 그러나 안타깝게도 현재의 시스템에는 ChannelMove 클래스뿐만 아니라 (그림 15)에 작성되어 있는 ChannelSearching 클래스 또한 동일한 $\operatorname{print}()$ 메서드를 가지고 있기 때문에 약한 교차점 강도로 인한 결함이 발생하게 된다.

\subsubsection{2 애스펙트 우선순위 결함의 발견}

(그림 13)의 AdultLockAspect 애스펙트와 ChannelLockAspect 애스펙트는 모두 (그림 14)의 회색 바탕의 코드인 print() 메 서드의 호출을 결합점으로 갖는다. 또 두 애스펙트 모두 결합 점에 $\operatorname{around}()$ 충고를 적용하고 있다. 따라서 ChannelMove 클래스의 print() 메서드가 호출될 때 AdultLockAspect 애 스펙트와 ChannelLockAspect 애스펙트가 모두 적용되어야 한다. 이처럼 동일한 결합점에 하나 이상의 애스펙트가 적 용될 때 애스펙트의 우선순위가 정해지게 되는데 따로 프로 그램 상에서 애스펙트 우선순위를 명시해 주지 않는 경우 둘 중 어떤 애스펙트가 먼저 실행될지 알 수 없기 때문에 애스펙트 우선순위의 결함이 나타나게 된다.

현재의 시스템에선 4.2에서 명시된 바와 같이 AdultLockAspect 애스펙트보다 ChannelLockAsepct 애스펙트가 항상 먼저 실 행되어야 한다. 그러나 (그림 15)의 확장된 프로그램의 수행 결과를 보면 ChannelLockAspect 애스펙트가 먼저 실행되는 것을 볼 수 있다.

\subsubsection{3 테스트 구현}

앞서 발견한 교차점 패턴 강도와 애스펙트 우선순위 결함 을 해결하기 위해 충고가 실행될 때의 교차점 정보와 결합점 정보를 수집해야 한다. 3장에서 제시한 바와 같이 $\mathrm{AOP}$ 의 반 사기능의 객체 중 AspectJ에서 지원하고 있는 thisJoinPoint 를 이용해 테스트 프로그램을 작성하였다.

확장된 ChannelLockAspect와 AdultLockAspect 애스펙트의 충고 내부에서 현재 교차점의 이름과 thisJoinPoint.getKind() 객체를 이용한 결합점의 종류, thisJoinPoint.getSourceLocation()

adultLockAspect : pointcut adultChannel(int nextChannel):call(* ChannelMove.print(..))

channelLockAspect : pointcut lockedChannel(int nextChannel):call(* *.print(..));

(그림 13) adultLockAspect와 channelLockAspect의 교차점패턴

〈표 2〉교차점 명세

\begin{tabular}{|l|l|l|l|}
\hline \multirow{2}{*}{ 교차점 이름 } & 선택되어야 하는 결합점 & 교차점 이름 & 선택되어야 하는 결합점 \\
\hline \hline \multirow{2}{*}{ lockedChannel } & ChannelMove.java:25 & \multirow{2}{*}{ ChannelMove.java:25 } \\
\cline { 2 - 2 } & ChannelMove.java:46 & adultLockList & ChannelMove.java:46 \\
\cline { 2 - 3 } & ChannelMove.java:56 & & ChannelMove.java:56 \\
\cline { 2 - 3 } & & &
\end{tabular}

class ChannelMove

print(String data, int nextChannel);

channelUp(String[]_channelList, int_currentChannel) print(_channelList[i], i); // ChannelMove.java:25

channelDown(String[]_channelList, int_currentChannel) print(_channelList[i], i); // ChannelMove.java:46

channelNumber(String[] _channelList, int _currentChannel) print(_channelList[i], i); // ChanneIMove.java:56 class ChannelSearching print(String list, int i); ChannelSearching(String[] channelList);

ChannelView(String[] channelList) print(ChannelList[i], i); // ChannelSearching.java:30 \} 


\begin{tabular}{|c|c|c|c|c|c|c|}
\hline & PointcutName & JoinpointKind & JoinpointLocation & lockedChannel & method-call & ChannelMove,java:46 \\
\hline$\nabla$ & lockedChannel & method-call & ChanneISearching.java:30 & adultLockList & method-call & ChannelMove.java:46 \\
\hline & lockedChannel & method-call & ChanneISearching.java:30 & lockedChannel & method-call & ChannelMove,java:46 \\
\hline & lockedChannel & method-call & ChanneISearching.java:30 & adultLockList & method-call & ChannelMove,java:46 \\
\hline & lockedChannel & method-call & ChannelSearching.java:30 & lockedChannel & method-call & ChannelMove.java:46 \\
\hline & lockedChannel & method-call & ChanneISearching.java:30 & adultLockList & method-call & ChannelMove,java:56 \\
\hline & adultLockList & method-call & ChannelMove.java:25 & lockedChannel & method-call & ChannelMove,java:56 \\
\hline & lockedChannel & method-call & ChanneIMove.java:25 & adultLockList & method-call & ChannelMove.java:56 \\
\hline & adultLockList & method-call & ChanneIMove.java:25 & lockedChannel & method-call & ChannelMove,java:56 \\
\hline & lockedChannel & method-call & ChanneIMove.java:25 & adultLockList & method-call & ChannelMove,java:56 \\
\hline & adultLockList & method-call & ChanneIMove,java:25 & lockedChannel & method-call & ChannelMove.java:56 \\
\hline & lockedChannel & method-call & ChanneIMove,java: 25 & adultLockList & method-call & ChannelMove,java:25 \\
\hline & adultLockList & method-call & ChannelMove.java:46 & lockedChannel & method-call & ChannelMove.java: 25 \\
\hline
\end{tabular}

(그림 16) 수집한 교차점과 결합점 정보

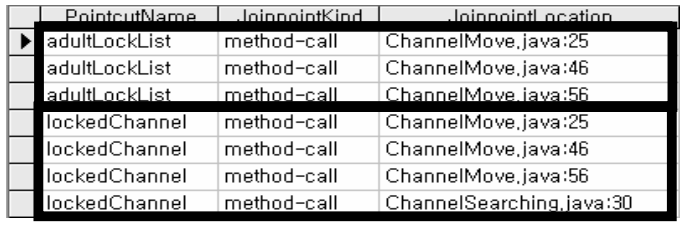

(a) 교차점 이름을 중심으로 정렬

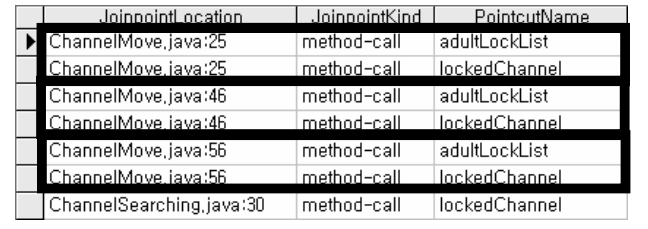

(b) 결합점을 중심으로 정렬

(그림 17) 교차점 패턴 강도 결함의 테스트 및 애스펙트 우선순위 결함의 테스트

객체를 이용한 결합점 소스코드의 위치를 가져와 데이터베 이스에 저장하였다.

(그림 16)은 확장된 애스펙트의 충고부분에 교차점과 결합 점 정보를 가져오는 소스를 추가한 후 수행한 결과이다. 그 림에서 보이는 것처럼 충고가 실행되는 순서대로 교차점 이 름과 결합점의 종류, 결합점의 소스코드 위치가 수집되어 있 다. 이렇게 수집된 소스코드를 적절히 정렬하면 교차점패턴 강도결함 및 애스펙트 우선순위 결함을 테스트할 수 있다.

(그림 17)의 (a)테이블을 보면 교차점 이름을 중심으로 결합점들이 나열되어 있는 것을 확인할 수 있다. 이를 교차 점 명세와 비교해 보면, <표 2>의 lockedChannel 애스펙트 의 교차점은 ChannelSearching.java:30에 해당하는 결합점을 취하지 않기 때문에 이는 약한 강도의 교차점 강도 결함이 나타나고 있음을 볼 수 있다. 또 (그림 17)의 (b)와 같이 결 합점을 중심으로 정렬하면 결합점별 교차점이 실행 순서대로 나타나게 된다. 이를 (그림 15)에 정의된 애스펙트 우선순위 와 비교해 보면 애스펙트 우선순위결함을 테스트해 볼 수 있 다. 현재 애스펙트 우선순위는 항상 channelLockAspect 애스 펙트가 adultLockAspect 애스펙트보다 우선시 되어야 하는 데 실험 결과에서 확인해 본 바로는 adultLockAspect 애스 펙트가 우선되어 실행되고 있기 때문에 애스펙트 우선순위 결함이 발생하고 있음을 확인할 수 있다.

\subsection{2 증명 규칙을 이용한 사후 조건 테스트}

ChannelNumber() 메서드의 사후 조건은 $\{0<$ nextChannel $<100\}$ 이다. 이 조건이 만족되는지 알아보기 위해 증명 규 칙을 작성하였다. (그림 18)은 애스펙트가 삽입된 channelNumber() 메서드의 코드이다. 회색 바탕의 소스들이 애스펙트를 삽입한 것이고, 굵은 글씨로 나타난 것이 각 부분에서의 조건들을 말 한다. (그림 18)에서와 같이 사전 조건은 $\{$ input $>0\}$ 이고, 사

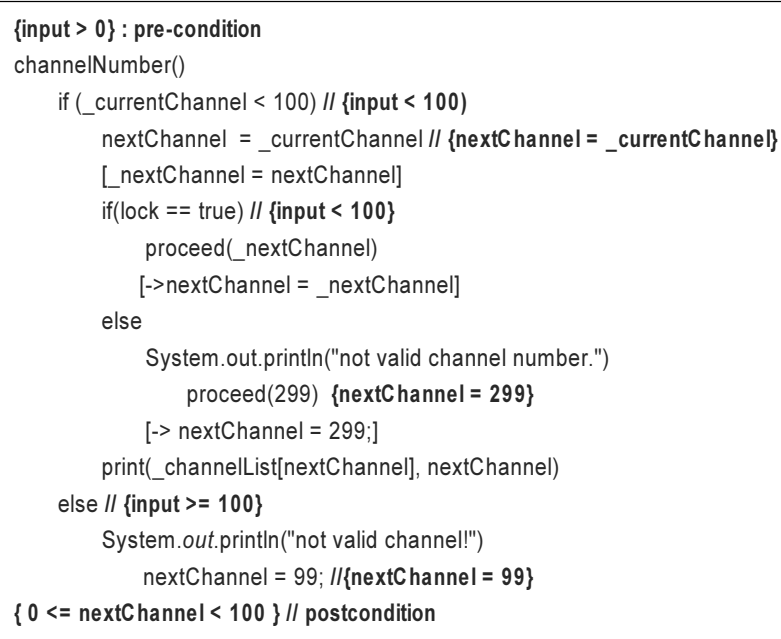

(그림 18) 증명 규칙을 적용한 사후 조건 테스트

후 조건은 $\{0<$ nextChannel $<100\}$ 이다. 사후 조건을 추적해 나가면 \{input $>0\}$ nextChannel $<100$ or nextChannel $=299$ or nextChannel = $99\{0<=$ nextChannel $<99\}$ 가 된다. 이 때, nextChannel $=299$ 는 사후 조건 $0<=$ nextChannel $<99$ 에 맞지 않기 때문에 사후 조건의 결함이 나타나는 것을 확인 할 수 있다.

\section{$4.3 .3 \mathrm{set}()$ 교차점을 이용한 불변 조건 테스트}

현재 시스템에서의 불변 조건중 하나는 nextChannel 이 라는 전역변수의 값이 항상 $0<=n e x t C h a n n e l<100$ 을 유지해 야 하는 것이다. 이를 확인하기 위하여 $\mathrm{AOP}$ 의 $\operatorname{set}()$ 교차점 을 이용해 애스펙트 테스트 인스트루멘트를 작성하였다.

(그림 19)는 불변 조건을 테스트하기 위한 테스트 인스트 루멘트이다. set() 교차점에 $\operatorname{args}()$ 를 이용하여 필드쓰기 참 


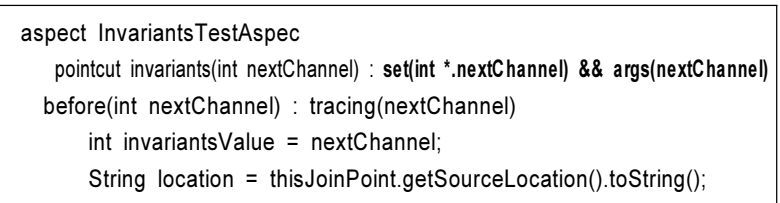

(그림 19) 불변 조건 테스트 인스트루멘트

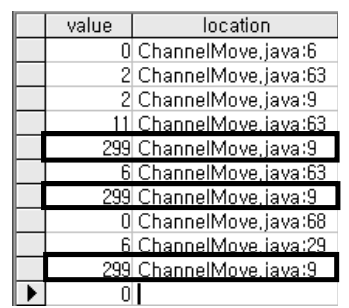

(그림 20) 불변 조건 테스트 인스트루멘트 실행 결과

조가 일어난 시점의 값을 가지고 오고 있다. 또한 반사기능 객체를 이용해 필드의 쓰기 참조가 일어난 지점의 위치도 알아본다. 이러한 정보를 데이터베이스에 넣으면 (그림 20) 과 같다. 테이블 좌측의 value 부분이 nextChannel에 쓰기 참조가 일어났을 때의 값이고, location이 그 위치를 말한다. 현재의 시스템에선 299란 값이 있는 것으로 보아 불변 조건 이 지켜지지 않고 있다.

\subsection{4 제어흐름 그래프를 이용한 제어 의존성 테스트}

레거시 시스템의 제어 의존성이 올바르다 하더라도 충고 의 삽입으로 인해 제어 의존성이 변할 수 있다. 제어 의존 성의 변화는 프로그램의 수행 결과상에서 쉽게 드러나지 않
기 때문에 발견하기 까다로운 결함 중 하나이다. 따라서 $\mathrm{AOP}$ 확장 후 $\mathrm{AOP}$ 가 적용된 제어흐름 그래프를 통해 제어 의존도를 확인해야 한다.

(그림 21)은 이 실험에서 주의 깊게 살펴보아야 할 코드 부분과 그 제어흐름 그래프이다.

(그림 21)의 소스코드를 분석해 보면 입력받은 채널이 100 미만일 경우 $\operatorname{print}($ ) 메서드가 호출되어 입력받은 채널의 프로 그램이 출력되고, 100 이상일 경우는 유효하지 않은 범위의 채널이기 때문에 유효하지 않은 채널이라는 메시지와 시그널 을 찾을 수 없다는 메시지가 출력될 것이다. (그림 21)의 제어 흐름 그래프에서 보면 제어 의존도가 분명히 드러나게 된다. 56번째 줄의 소스코드는 54번째 줄의 if문이 참인 경우만 수행 되어 54번째 줄의 if문에 의존적이다. (그림 22)의 소스코드는 print() 메서드가 호출될 때 호출되는 channelLockAspect 애 스펙트이다. channelLockAspect의 around() 충고를 보면 32번 째 줄의 if문이 존재한다. 이로 인해 56 번째 줄의 제어 의존은 애스펙트의 32 번째 줄로 바뀐 것을 볼 수 있다. 이는 입력받 은 채널의 값이 300 이 넘는지를 확인하고 있다. 레거시 시스 템에서의 채널은 100 이상이 되면 안 되지만, 애스펙트를 작 성할 당시 충분히 레거시 시스템을 이해하지 못했기 때문에 나타난 결함으로 볼 수 있다.

\section{5. 결론 및 향후과제}

빠르게 변화하는 사용자의 요구에 맞추기 위해, 사용자가 원하는 기능을 빠른 시간에 추가하여 제품을 출시하기 위해, $\mathrm{AOP}$ 는 기능 추가함에 있어 기존의 소프트웨어를 수정하지 않고 가능하다는 큰 이점을 가지고 있다. 이렇게 $\mathrm{AOP}$ 를 이
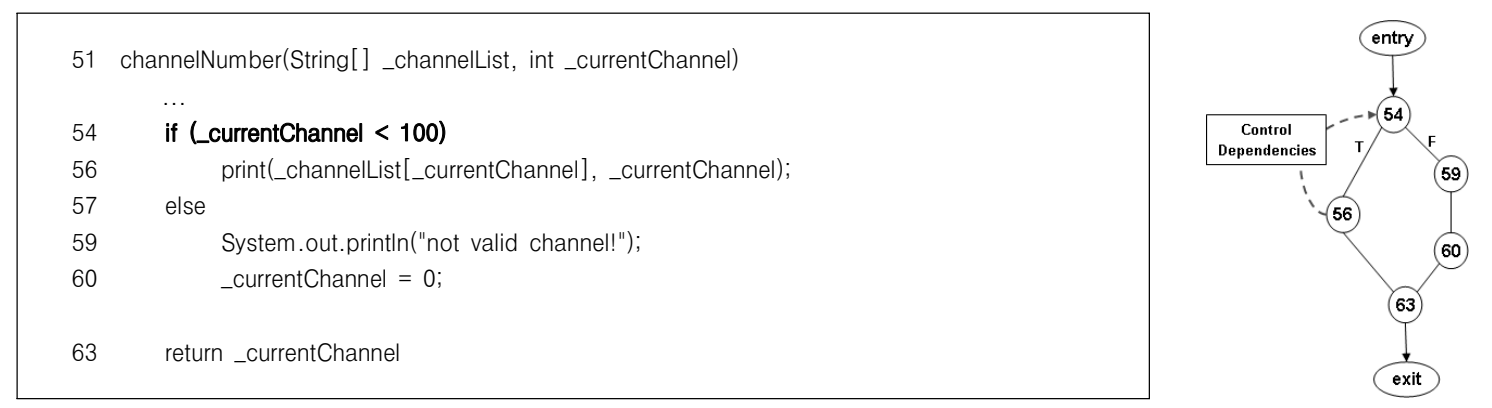

(그림 21) channelNumber() 메서드 channelNumber() 메서드의 제어흐름 그래프
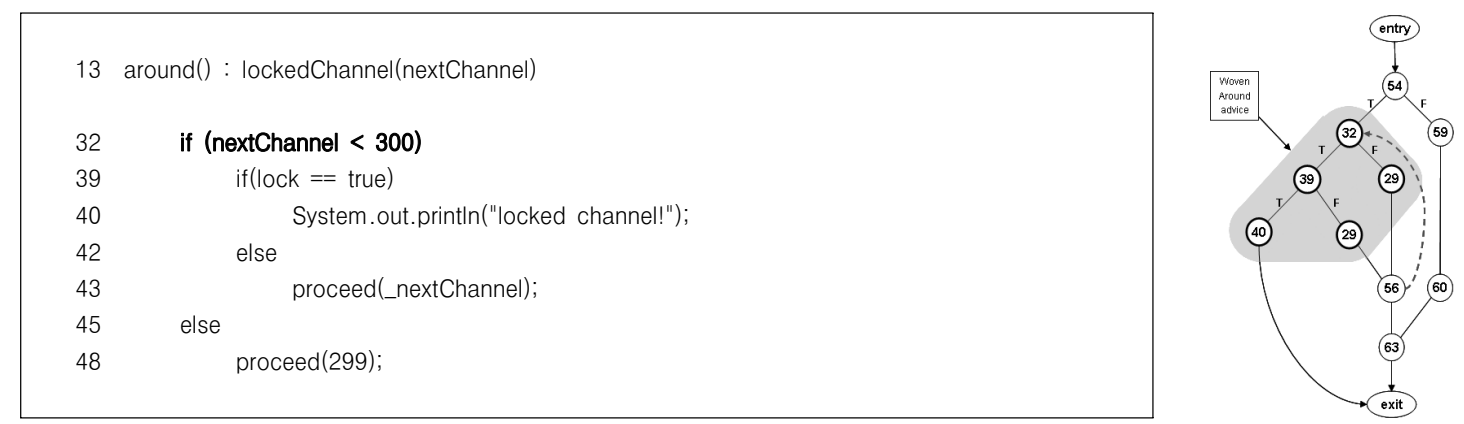

(그림 22) channlLockAspect 애스펙트의 충고 및 충고 삽입 이후의 제어흐름 그래프 
용해 확장한 경우의 회귀테스트를 위해서 $\mathrm{AOP}$ 의 특징을 잘 이해하고 그에 맞는 회귀테스트 방식을 적용해야 한다.

이 논문에서는 $\mathrm{AOP}$ 를 이용해 확장된 프로그램의 회귀테 스트를 위해서 $\mathrm{AOP}$ 결함 모델을 참고로 하여 실험을 설계 하였다. 모두 네 가지의 테스트 방법을 제시하여 $\mathrm{AOP}$ 결함 모델의 다섯 가지 영역을 커버하고 있다. 첫 번째로 반사기 능의 객체를 이용해 교차점과 결합점 정보를 수집하는 기법 을 제시하였다. 교차점과 결합점의 정보를 수집하여 교차점 이름으로 수집한 정보를 묶으면 교차점 강도 패턴의 결함을 밝혀낼 수 있었고, 결합점을 중심으로 묶으면 애스펙트 우 선순위의 결함을 테스트할 수 있었다. 두 번째 방법은 증명 규칙을 이용하여 매개변수의 사후 조건을 테스트하는 것이 다. 레거시 시스템에 삽입된 충고의 소스를 추가하여 애스 펙트 확장된 프로그램을 증명 규칙을 적용하여 테스트 하였 다. 세 번째로 $\operatorname{set}()$ 교차점을 이용한 불변 조건의 테스트 방법은 $\operatorname{set}()$ 교차점과 $\operatorname{args}()$ 를 이용해 특정한 필드를 추적 하여 변하는 값을 저장하는 테스트 인스트루멘트를 작성하 는 것이다. 이렇게 가져온 값이 조건에 맞는지 확인하여 불 변 조건을 테스트 할 수 있었다. 네 번째 방법은 제어흐름 그래프를 이용한 방법으로 레거시 시스템의 제어흐름 그래 프에 애스펙트 제어흐름 그래프를 삽입하여 애스펙트까지 확장된 제어흐름 그래프를 통해 제어 의존성 결함을 확인해 보았다.

논문을 통해 $\mathrm{AOP}$ 로 진화된 프로그램의 회귀테스트 방법 에 대해 적용해 볼 수 있을 것이다. 향후 교차점 강도 패턴 의 결함을 수정함에 있어 [15]를 적용하면 교차점 강도 패턴 을 추천해 주는 방안도 연구해 볼 수 있을 것이다. [13]에서 와 같이 큰 소프트웨어의 회귀테스트에 mock를 적용한 테 스트에 대한 연구 역시 제시한 방법에 적용해 볼 수 있을 것이다. 또한 제시한 방법의 테스트 도구와 자동화된 테스 트 방법에 대한 연구도 좋은 연구과제가 될 것이다.

\section{참 고 문 헌}

[1] G. Xu, Z. Yang, "A novel approach to unit testing: The Aspect-Oriented way," International Symposium on Future Software Technology 2004, Xian China, October, 2004.

[2] N. Belblida, et. al, "AOP extension for security testing of programs," Proc of IEEE Canadian Conference on Electrical and Computer Engineering, Ottawa, May, 2006.

[3] J. Zhao, "Data-Flow-Based Unit Testing of Aspect-Oriented Programs," In Proc. 27th Annual IEEE International Computer Software and Applications Conference(COMPSAC'2003), Dallas, Texas, December, 2003.

[4] J. Bruel, et al., "Using aspects to develop built-in tests for components," $4^{\text {th }}$ Modeling with UML workshop of 2003 UML conference, San Francisco, Oct., 2003,

[5] R. T. Alexander, J. M. Bieman, and A. A. Andrews. "Towards the systematic testing of aspect-oriented programs," Technical Report, CS-4-105 Department of Computer
Science, Colorado State University, March, 2004.

[6] Ramnivas Laddad, "AspectJ in Action: Practical AspectOriented Programming”, Manning Publications, 2003.

[7] G. Kiczales, E. Hilsdale, J. Hugunin, M. Kersten, J. Palm, and W. Griswold, "An Overview of AspectJ," In 15th European Conference on Object-Oriented Programming, Budapest, Hungry, 2001.

[8] D. Xu, W. Xu, and K. Nygard, "A State-Based Approach to Testing Aspect-Oriented Programs," Technical Report, Department of Computer Science North Dakota State University, September, 2004.

[9] D. Xu, "Test Generation from Aspect-Oriented State Models," Technical Report, NDSU-CS-TR-05-XU02, Sept., 2005.

[10] H. Song, Y. Yin, S. Zheng, "Dynamic aspects weaving in service composition," Proc. of the $6^{\text {th }}$ International Conference on Intelligent Systems Design and Applications(ISDA'06), IEEE, 2006.

[11] J. S. Bekken, Roger T. Alexander. "A Candidate Fault Model for AspectJ Pointcuts," $17^{\text {th }}$ International Symposium on Software Reliability Engineering (ISSRE'06), 2006.

[12] J. Zhao and M. Rinard, "System Dependence Graph Construction for Aspect-Oriented Programs," MIT LCS Technical Report 891, March, 2003.

[13] Michael Mortensen and Sudipto Ghosh, James M. Bieman, "Testing During Refactoring Adding Aspects to Legacy Systems," $17^{\text {th }}$ International Symposium on Software Reliability Engineering(ISSRE'06), 2006.

[14] Otavio Augusto Lazzarini Lemos and Cristina Videira Lopes "Testing Aspect-Oriented Programming Pointcut Descriptors," International Symposium on Software Testing and Analysis Proceedings of the $2^{\text {nd }}$ workshop on Testing aspect-oriented programs, 2006.

[15] P. Anbalagan and T. Xie. "Efficient mutant generation for mutation testing of pointcuts in aspect-oriented programs," In Proc. $2^{\text {nd }}$ Workshop on Mutation Analysis, November, 2006.

[16] Reza Meimandi Parizi, Abdul Azim Ghani, "A Survey on Aspect-Oriented Testing Approaches," $15^{\text {th }}$ International Conference on Computational Science and Applications, IEEE, 2007

[17] W. Xu, D. Xu, V.Goel, and K. Nygard, "ASPECT FLOW GRAPH FOR TESTING ASPECT-ORIENTED PROGRAMS," In Proceeding of the $8^{\text {th }}$ IASTED International Conference on Software Engineering and Applications(SEA 2004), ACTA Press, August, 2004.

[18] W. Xu and D.Xu, "A model-based approach to test generation for aspect-oriented programs," AOSD 2005 Workshop on Testing Aspect-Oriented programs, Chicago, March, 2005. 


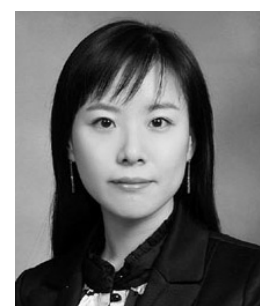

이 미 진

e-mail : alexshel@naver.com

2006년 동국대학교 컴퓨터공학과(학사)

2008년 동국대학교 대학원 컴퓨터공학과 (공학석사)

2008년 현 재 NHN게임서비스 개발팀 관심분야: $\mathrm{AOP}$, 소프트웨어테스팅 등

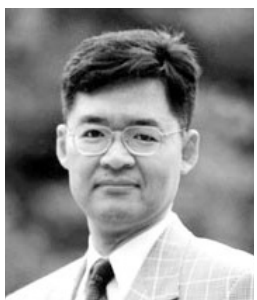

최 은 만

e-mail : emchoi@dgu.ac.kr 1982년 동국대학교 전산학과(학사)

1985년 한국과학기술원 전산학과(공학석사)

1993년 일리노이 공대 전산학과(공학박사) 1985년 1988년 한국표준연구소 연구원 1988년 1989년 데이콤 주임연구원

1998 2004년 한국정보과학회 소프트웨어공학연구회 운영위원 2001 2003년 한국정보처리학회 학회지편집위원 2000, 2007년 콜로라도 주립대 전산학과 방문교수 2002년 카네기멜론대학 소프트웨어공학 과정 연수 1993년 현재 동국대학교 컴퓨터공학과 교수

관심분야: 객체지향 설계, 소프트웨어 테스트, 프로세스와 메트릭,

Program Comprehension 